\title{
Accounting for the context in phenomenography-variation theory: evidence of English graduates' conceptions of price
}

\author{
Guy Durden \\ Department of Curriculum, Pedagogy and Assessment, UCL - Institute of Education, \\ London, UK
}

\begin{abstract}
In describing peoples' conceptions of phenomena, most phenomenography/variation theory research does not distinguish between generalised aspects of conceptions and contextualised aspects. This study suggests this approach may have limitations. The concepts of the external and internal horizon are used to provide evidence that graduates' conceptions of price consist of a combination of generalised and contextualised elements, where each horizon can be described in terms of qualitative differences. This way of approaching conceptions allows for a crisp delimitation of a phenomenon from its context, captures their relationship, and is consistent with the principles of

phenomenography/variation theory. Findings raise questions about connections between internal and external horizons and the 'correct' way to sequence variation in order to trigger conceptual change.
\end{abstract}

\section{Keywords}

Phenomenography, context, external horizon, conceptions of price, learning study

Department of Curriculum, Pedagogy and Assessment

UCL - Institute of Education

20 Bedford Way

London

WC1H 0AL

E-mail: g.durden@ucl.ac.uk

Telephone: +44 (0)7808 197452 


\section{Introduction}

Phenomenography is an approach to theorising and researching peoples' conceptions of phenomena in the world. It has been applied in a wide variety of educational settings, including schools and universities, as well to healthcare and information systems professionals. Phenomenographers develop descriptions of qualitatively different conceptions of any given phenomenon that are a very useful basis for instructional design. One approach, known as variation theory, involves highlighting differences between conceptions of a phenomenon in order to trigger conceptual change. Phenomenography/variation theory (PVT) is most commonly enacted through 'Learning Study' (Pang \& Marton 2003, 2005) - a collaborative approach to the preparation of school lessons that has gained significant international prominence (Lo, 2009).

PVT emphasises the importance of incorporating the context of a phenomenon in descriptions of peoples' conceptions (Lo \& Marton, 2012). In order to do this one of the things that it must account for is the way in which people experience different instances of the same phenomenon. For example, people can experience a mountain in Slovakia and a mountain in Austria, even though one person may be looking at the mountain as a physical barrier between countries and another may be looking at it in terms of its natural beauty. In this case, contextual factors are a part of peoples' conceptions of a mountain, but there is also a part that is separate (although related), to do with the nature of mountains. This suggests that to fully capture people's conceptions, phenomenographers should be able to describe: i) qualitatively different aspects of conceptions that are generalizable in any context and, ii) how those aspects are embedded in a particular context (Marton \& Pong, 2005).

This study has two main objectives: i) to argue that PVT research could benefit from more clearly distinguishing between generalised and contextualised elements of conceptions both in the approach to the conduct of research and in the way in which conceptions are described and, ii) to provide evidence of an approach to describing conceptions that accounts for the separate but related nature of these aspects. In examining the way in which conceptions are described, this study contributes more to phenomenography than variation theory. It therefore goes some way to addressing the bias towards variation theory noted in recent years (Rovio-Johansson \& Ingerman, 2016).

The study could also contribute to a more effective application of PVT to instructional design by increasing teachers' knowledge of students' conceptions. If teachers have better knowledge of generalised and contextualised elements of conceptions they will be better placed to: i) help students transfer their understanding to new contexts and, ii) avoid inadvertently capping the development of students' understanding by choosing a context in which to present a phenomenon that restricts that development.

The next section examines how previous PVT research has used the concepts of the 'internal horizon' and 'external horizon' (Marton \& Booth, 1997) to account for the context of a phenomenon, before outlining the approach taken in this study. Following this, evidence of 118 good quality English graduates' conceptions of price is presented. This indicates that conceptions of price consist of a combination of generalised and 
contextualised elements where each can be described in terms of qualitative differences. This structure allows for a crisp delimitation of a phenomenon from its context, whilst capturing the relationship between the two. Price was chosen as the phenomenon to study because of its prominence in previous PVT research.

\section{Phenomenography/variation theory and context}

PVT offers a theoretical framework for analysing the context of a phenomenon in terms of an 'internal' and an 'external' horizon (Marton \& Booth, 1997). Based on Gurwitsch's (1964) structure of awareness model, this proposes that a person can be simultaneously aware of a particular set of aspects of a phenomenon within a 'thematic field'. At any moment within the thematic field, awareness forms into a 'theme' that consists of: i) relationships between a sub-set of aspects of the phenomenon and, ii) relationships between these and the phenomenon as a whole. This 'structural aspect' (which might vary in terms of the number of aspects, the relationships between them or the strength of those relationships), along with a 'referential aspect' denoting the meaning inherent in the structure, make up a 'conception' in phenomenography (Marton \& Booth, 1997). Outside of the thematic field, in the 'margin', are aspects of the world that are not related to the phenomenon in question, but can nevertheless be part of peoples' awareness. Marton and Booth (1997) refer to the 'theme' as the internal horizon and the 'thematic field' and the 'margin of awareness' as the external horizon. This is summarised in Figure 1 below.

Figure 1 - 'A structure of awareness' (from Cope \& Prosser, 2005 p. 349)

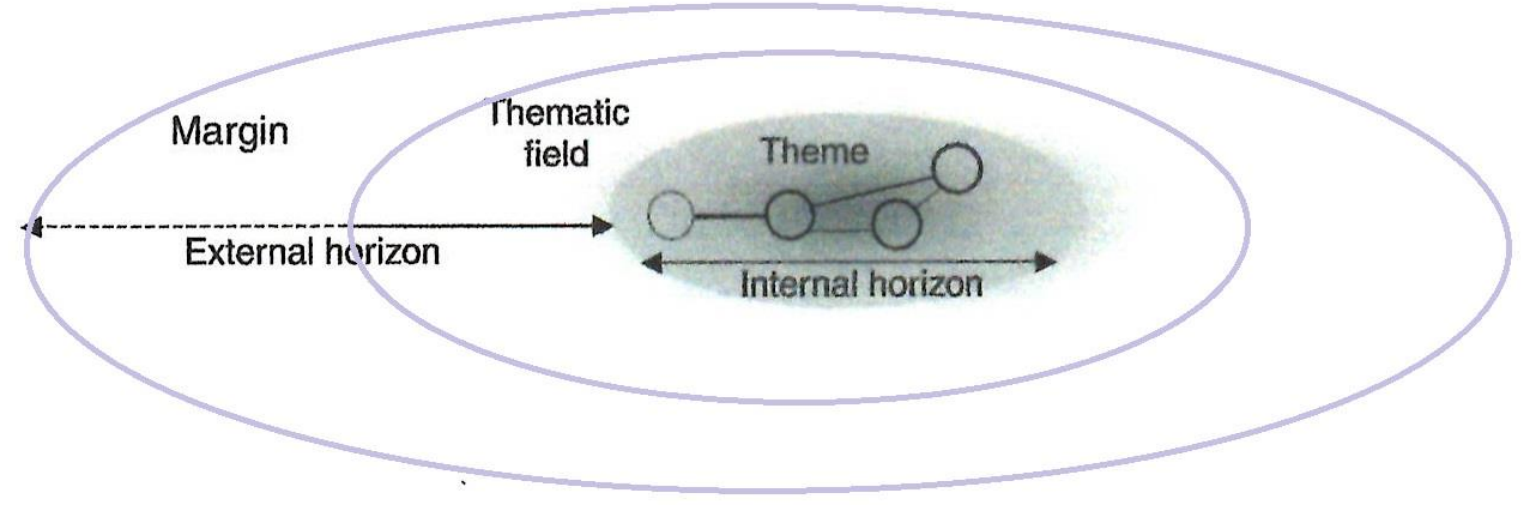

PVT researchers have interpreted this model in different ways and this has affected how they have described conceptions. For some, the more sophisticated conceptions are, the more aspects of the external horizon they incorporate. There are those who see this in terms of the inclusion of more aspects of the external horizon (e.g. Cope \& Prosser, 2005; Lo \& Chik, 2016), and there are those that see it in terms of increasing the number of aspects but also reconfiguring the relationships between the aspects within the theme (e.g. Dahlgren et al., 2006; Markaukaite \& Wardak, 2015). Since these interpretations assume an expanding boundary between the internal and external horizon, they are unlikely to result in descriptions of conceptions that include an explicit reference to either the internal or the 
external horizons. This was confirmed by a quick review of a random selection of three recently published PVT studies where there was no mention of the terms internal horizon, external horizon or context (Abreu Novais et al., 2018; Arvelklev et al., 2017; Morrrison \& Secker, 2017). The same applies to a number of important studies of the phenomenon of price (Pang \& Marton, 2003, 2005; Pang, Linder \& Fraser, 2006; Marton \& Pang, 2008).

On this view of the external horizon, the success of PVT research relies on approaching a phenomenon from different angles until the researcher is as convinced as they can be that they have captured all possible aspects of conceptions (Åkerlind, 2005). If the phenomenon has been 'saturated' (Taylor \& Booth, 2015, p.1305), then it could be assumed that this has included a consideration of the context.

To illustrate this, consider an example drawn from a previous study that is typical of PVT research into price. The conceptions in Table 1.0 below are arranged in order of increasing sophistication (where 2A and 2B are of equal complexity). On the expanding boundary view of conceptions, Conception 3 contains a greater number of aspects (possibly configured in a different way) and is more sophisticated because it includes more of the aspects in the external horizon. This interpretation implies that Conception 3 will be visible in all possible situations in which a product has a price.

Table 1.0 - Conceptions of price (Marton E Pang, 2008)

\begin{tabular}{|l|l|}
\hline 1 & Price as a function of variation in the characteristics of a product \\
\hline 2 A & Price as a function of willingness to buy and purchasing power \\
\hline 2B & Price as a function of the availability of a product \\
\hline 3 & $\begin{array}{l}\text { Price as a function of willingness to buy and purchasing power as } \\
\text { well as the availability of a product. }\end{array}$ \\
\hline
\end{tabular}

One of the challenges for this approach is making sure that important aspects of the external horizon are identified and incorporated into descriptions of conceptions. This could be a function of PVT researchers' awareness of the external horizon. Marton and Pong (2005) found that apparent inconsistencies in the conceptions people expressed may have resulted from the way in which researchers interpreted evidence from participants. They suggest that researchers took evidence to be related to generalised conceptions of a phenomenon (price), whereas infact participants were providing evidence of contextualised conceptions. This implies that the way in which PVT researchers conceptualise the external horizon will affect what they find. If they do not consider contextual factors as being distinct from factors related only to the phenomenon, then they may be less likely to identify any. Since most PVT studies do not report explicitly on the external horizon it is difficult to know how prevalent this issue is.

Another important factor is the quality of PVT researchers' knowledge of context. Lo and Chik (2016) provide evidence that this cannot be taken for granted in their analysis of the limitations of science teachers' knowledge of context in astronomy. The implication of 
their study is that if these teachers act as researchers, their ability to identify complete contextualised descriptions of conceptions in others would be restricted. Since PVT studies with an expanding boundary view of the external horizon do not focus separately on the context, any gaps in researchers' knowledge are less likely to be highlighted. With PVT studies that do not report on the external and internal horizon, it is difficult to gauge the depth of researchers' knowledge of the context.

Perhaps the most significant issue with way in which conceptions are described in Table 1.0 is that they do not clearly distinguish between generalised aspects of conceptions that are applicable in any circumstances and contextualised aspects of conceptions that may relate only to some. This is important because if generalised and contextualised aspects are not explicitly separated in descriptions of conceptions then it is much more difficult to analyse the relationships between them. By not separating these elements, the conceptions in Table 1.0 seem to exclude the possibility that: i) conceptions may be visible in different contexts but have different meanings in different contexts and, ii) that some contexts may be more strongly associated with some conceptions than others. For example, it is not clear how or if the interaction between willingness and ability to buy and availability (Conception 3) would be different in relation to the price of the same product in different countries (assuming that different countries represent different contexts). Also if a particular context (Context A) is strongly associated with Conception 2A, whilst another context (Context B) is strongly associated with Conception 3, a PVT study set only in Context A is much less likely to reveal Conceptions $2 \mathrm{~A}$ and 3 than one that is set in both contexts. That the same person presents different conceptions of the same phenomenon in different contexts is strong evidence for this (Marton \& Pong, 2005).

These problems have been addressed by a small number of PVT studies that have assumed that the external horizon is a phenomenon in its own right that can be separated from the phenomenon related to the internal horizon. This opens up the possibility that people can have conceptions of the external horizon in the same way that they can in relation to the internal horizon (e.g. Cope, 2004, Willhelmson et al., 2011; Taylor \& Booth, 2015). On this interpretation, a particular conception is linked to a particular quality of understanding of the internal horizon and to a particular quality of understanding of the external horizon.

This conceptualisation of the external and internal horizons has two main advantages. First, it means that PVT researchers must explicitly consider the external horizon as a separable entity in the conduct of research and report on how they have included it in their research design. Second, it allows PVT researchers to map and explore the relationships between generalised conceptions and contextualised conceptions of a phenomenon in a way that is not immediately possible if conceptions are expressed in a similar way to Table 1.0. In view of these advantages, this study adopted this interpretation of the external horizon in the analysis of graduates' conceptions of price. The next section presents evidence for this approach. 


\section{Method}

This study adopted a phenomenographic research design in order to identify and describe qualitative differences between graduates' conceptions of price. Evidence was drawn from written responses to two contextualised price problems in conjunction with transcripts from semi-structured interviews. Stable descriptions of conceptions emerged after repeated analysis of the evidence by two experienced PVT researchers.

The participants in this study were graduates of economics and business studies training to gain teacher accreditation on nine month Post Graduate Certificate of Education courses at eight universities during 2012-13. The sample of 118 represents nearly $50 \%$ of the total number of graduates training in England in economics and business studies in that year. Evidence was gathered at the end of the third month of training. The study followed the guidelines of the British Education Educational Research Association (2011) and was organised to minimise the impact on all of the participants and preserve their confidentiality.

Within each university, graduates were randomly divided into two equal sized groups, with each group being given about 30 minutes to respond to a written price problem. In these problems, closely related products were set in different contexts (Cope, 2004) with the aim of revealing differences in graduates' understandings of both the phenomenon of price and its context. One problem was set in the context of an individual business decision and the other in the context of a market. Previous research into undergraduates' conception of price suggested that these contexts are important (Davies, 2011).

The wording of the two written problems closely followed that in previous studies of price (Pang, Linder \& Fraser, 2006; Pang \& Marton, 2005):

Problem 1 (P1) - Over 2.25 billion cups of coffee are drunk in the world each day. Coffee is mainly grown by farmers in developing countries. In 2011 the price of coffee beans sold on the world market was about $\$ 6$ a kilo. Why do you think that the price was about $\$ 6$ a kilo? What could explain why the price was not $\$ 5$ or $\$ 7$ a kilo? What factors could affect the price? Please explain why the price of coffee was about $\$ 6$ a kilo in as much detail as you can.

Problem 2 (P2) - Suppose that you were the new owner of the school canteen and were deciding what prices to charge. The previous owner charged $£ 0.75$ for a cup of coffee. What price would you set for a cup of coffee? Would you set the current price or a different price? What would you consider when you set the price? Please explain why you would set this price in as much detail as you can.

Twenty five written responses were randomly chosen and set aside to test the validity of the final categories at the end. The reliability of the written evidence was checked by conducting semi-structured interviews with 16 of the graduates, two randomly chosen from each university. Interviews lasted between 25 and 35 minutes and were conducted in each university by an experienced PVT researcher. Interviews contained a small number of standard questions with additional unstructured follow up questions. Following Åkerlind 
(2005), two types of questions were asked: i) open questions to establish what the phenomenon of price meant to the graduate and, ii) situated questions to elicit concrete illustrations of graduates' thinking. Interviews were transcribed in their entirety. The analysis of evidence took over eight months ensuring that it was looked at 'from different perspectives at different times' (Åkerlind, 2005, p.328). To aid this process, an additional experienced researcher was involved in drafting and reviewing emerging descriptions of conceptions (Bowden \& Walsh, 2000).

Both interview transcripts and written responses were treated in the same way. They were repeatedly read by both researchers, with a high degree of openness to possible differences between conceptions. Following this, draft categories were drawn up and then repeatedly reviewed. This involved grouping and re-grouping perceived similarities and differences between conceptions. For some of the time this meant working with the entire response, whilst at other times it meant focusing on extracts. These groupings would sometimes occur before the actual description of a category was finalised and sometimes afterwards to validate tentative draft descriptions (Åkerlind, 2005). Throughout, the researchers were consistently mindful of the importance of recognising the difference between the words that graduates used and the underlying meaning (Bowden \& Walsh, 2000). Drafting was done away from written evidence in order to preserve as much objective distance as possible (Prosser, 2000). About half of the time both researchers worked together drafting and reviewing, and half of the time they independently reviewed each other's work.

Pertinent quotations from either the transcripts or the written responses were selected in order to make the data more manageable to deal with. However, in order to maintain a sense of the importance of context, at no point did quotations became the sole focus. Frequently during the analysis, researchers referred back to the complete text in order to confirm that it accurately captured the meaning when seen in the context of the whole response. In sharpening up draft categories, three sets of quotations proved valuable: i) those on the 'borderline' which did not immediately appear to fall into one category or another, ii) those that seemed to indicate either extremely straightforward or extremely complex conceptions and, iii) those that did not seem to fit into any categories at all. These three types of responses were often used as a focus for discussions between researchers.

To maintain a high a degree of awareness of possible meanings in the data, the early stages of this analysis were more focused on meaning than on the structural relationship between categories (Ashworth \& Lucas, 2000). As drafting progressed, both structure and meaning were simultaneously considered. Researchers were aware of the possibility of including data that did not obviously fit with the emerging categories as either sub-categories of the main categories, or non-critical variation in ways of understanding or as part of a

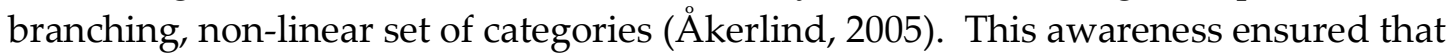
potential meanings in the data were not overlooked.

Ten iterative research cycles were completed during this study after which time the scale of the revisions and redrafting reduced and categories became stable. Each graduate was then allocated to a category according to their highest revealed conception (Pang \& Marton, 2003; 2005). The distribution of graduates' conceptions in relation to each of the price 
problems was calculated in order to examine associations between the context and the revealed conceptions.

In this study, the reliability of the results was increased by the way in which the two researchers reached agreement after extended discussions around their individual interpretations and re-interpretations of the evidence over an extended period of time. A high degree of inter-judge reliability was achieved in the analysis of the 25 written responses that had been set aside at the start of the research. The second researcher placed $88 \%$ of these written responses in the same category as the first researcher and the remaining $12 \%$ were no more than one category different.

\section{Results}

Results are presented in three sections: i) a description of the overall structure of the conceptions identified, ii) evidence of qualitative differences between conceptions referring to illustrative quotations from graduates and, iii) the distribution of conceptions.

\subsection{The structure of graduates' conceptions of price}

This study identified twelve conceptions of price set out in Table 2.0 below. Each conception was found to be made up of a generalised component (taken to be the internal horizon) and a contextualised component (taken to be the external horizon). Thus, for example, Conception D2 was made up of generalised component D and contextualised component 2. The study identified qualitative differences in both the generalised components and the contextualised components. Generalised components are arranged in order of increasing sophistication in Columns A - D in Table 2.0, whilst contextualised components are set out in order of increasing sophistication in Rows 1 - 3. 


\begin{tabular}{|c|c|c|c|c|c|c|c|c|}
\hline & \multicolumn{4}{|c|}{ Internal horizon } \\
\hline & & & & & \multicolumn{4}{|c|}{ Increasing sophistication } \\
\hline & & & & & A & B & C & D \\
\hline & & & & & $\begin{array}{c}\text { Either } \\
\text { supply or } \\
\text { demand } \\
\text { factors }\end{array}$ & $\begin{array}{l}\text { Supply } \\
\text { and } \\
\text { demand } \\
\text { factors } \\
\text { listed }\end{array}$ & $\begin{array}{l}\text { Interaction } \\
\text { between } \\
\text { supply } \\
\text { and } \\
\text { demand }\end{array}$ & $\begin{array}{c}\text { Interaction } \\
\text { between } \\
\text { supply and } \\
\text { demand } \\
\text { affected by } \\
\text { competition, } \\
\text { power and } \\
\text { equity }\end{array}$ \\
\hline \multirow{3}{*}{ 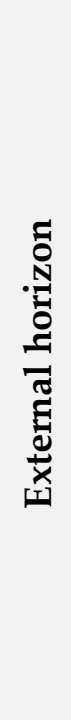 } & \multirow{3}{*}{ 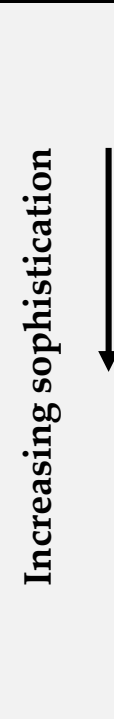 } & & 1 & $\begin{array}{c}\text { Pricing } \\
\text { decision } \\
\text { made by a } \\
\text { firm } \\
\end{array}$ & A1 & B1 & C1 & D1 \\
\hline & & & 2 & $\begin{array}{c}\text { Price } \\
\text { determined } \\
\text { within a } \\
\text { market } \\
\text { context } \\
\end{array}$ & A2 & B2 & $\mathrm{C} 2$ & D2 \\
\hline & & & 3 & $\begin{array}{c}\text { Price } \\
\text { determined } \\
\text { in context of } \\
\text { multiple } \\
\text { markets }\end{array}$ & A3 & B3 & C3 & D3 \\
\hline
\end{tabular}

Along the internal horizon, in Column A, graduates saw price as a function of factors related to businesses (supply) or factors related to customers (demand). There was a distinction between those who saw price as a function of both supply and demand (Column B), and those who saw it in terms of an interaction between the two (Column C). A small number of graduates saw this interaction in terms of competition, power and equity (Column D).

Along the external horizon, in Row 1, price was seen as being the outcome of a decision by firms. On this view, firms are 'price-makers'. This was distinct from Rows 2 and 3, where price was imagined as being the outcome of market behaviour set in a 'price-taker' context. On this view, price is determined more by factors outside of firms' direct control. Row 2 reflects a conception of price as the outcome in one market, for example, the retail market. This is in contrast to Row 3, where price is the outcome of interactions between multiple markets. For example, the price of a good in a retail market would be affected by the price in a wholesale market which in turn would be affected by prices in the market for raw materials. 


\subsection{Evidence of graduates' conceptions of price}

The first four quotations 1 - 4 highlight differences within the perspective of price setting by an individual or business (Row 1 in Table 2.0). Quotation 1 exemplifies a cost-plus model of pricing where farmers work out their costs and then add a margin to determine price. Since it does not consider customers' demand for coffee, this perspective refers to supply only and therefore falls within Conception A1. Quotation 2 also refers to supply (in referring to the 'cost of production'), however also considers customers' demand (in referring to 'market research'). Quotation 2 does not explicitly consider the relationship between demand and supply, presenting them as two discrete factors. This quotation is therefore taken to be illustrative of Conception B1. Quotation 3 also refers to both demand and supply. Demand is indicated at the start in the reference to a 'questionnaire' to be given to customers. Supply is indicated indirectly if it is assumed that lowering the 'quality of coffee' is synonymous with lowering the cost of coffee in order to ensure that profit is made. It is also referred to directly in terms of 'breakeven'. Breakeven is that level of sales where the amount of money coming in from customers is equal to the costs of the business. Since Quotation 3 implies that the business must consider the relationship between supply and demand in terms of whether or not it will break even, this quotation is taken to be indicative of Column C1 in Table 2.0. Finally, Quotation 4 expresses an interaction between customers and the business in that the business must match 'service and quality' (supply) to customer 'expectations' (demand). This interaction is influenced by the power that the business derives from being the sole (monopoly) supplier of coffee school, in balance with the need to consider customer needs. However, it is still very clear that the final decision in relation to price rests with the business itself. Quotation 4 is therefore indicative of Column D in Table 2.0 (Conception D1).

Quotation 1 (P2) - Conception A1

Producers of the product would know how much it takes to make coffee beans ie how much labour and capital employed is used to harvest the bean. They would be able to find out how much it costs to harvest a field full of coffee beans, then break the cost into kilos, they would then find how much it costs per kilo, taking into account fixed and variable costs (total costs). The farmers would then want to decide which price they feel that they could sell per kilo. They may have a mark-up price of 200 to 300 per cent.

Quotation 2 (P1) - Conception B1

Before setting the price of a cup of coffee I would look at the previous owner's sales; I would look and see on average how many cups of coffee he would sell on a weekly basis, and then work out would I want to sell more or the same as the previous owner....Secondly I would look at the cost of production, how much it would cost me to buy in the coffee.......I would carry out some market research, ask the consumers why they buy the coffee, what do they think of the coffee...

Quotation 3 (P1) - Conception C1

It would be interesting to find out from the school how many coffee drinkers previously purchased from the school canteen through questionnaires. This would give an overview of whether the number of customers would rise, if the price was lowered, and therefore raise 
sales/profits without lowering the quality of the coffee...I would review the amount of money needed through purchases in the canteen to break even.

\section{Quotation 4 (P1) - Conception D1}

A consideration must be made with regards to the customer, but as it is a monopoly I can set the price as I want providing the service and quality matches expectations - expectations being the key word. What do customers of a school canteen expect?

Below are quotations that exemplify conceptions of price setting in markets (Rows 2 and 3 in Table 2.0). Quotation 5 imagines a change in demand that would occur with constant consumer preference (through an increase in population). This is in contrast to Quotation 2 above, where a change in demand is viewed in terms of changes in consumer preference. Whilst Quotation 2 considers the cost of production for an individual company, Quotation 5 considers technical progress affecting all producers (through the reference to the 'mechanisation of the supply chain'). In both of these ways, Quotation 5 is illustrative of a broader market perspective and thus relates to Row 2 of Table 2.0 (Conception B2).

Quotations 3 and 6 are responses to $\mathrm{P} 1$ which posed an 'individual business' problem, yet Quotation 6 explicitly refers to interaction between supply and demand in stating 'if costs in general have gone up it would be realistic to marginally increase the price of all products where the products are not price sensitive'. This is a more complex form of understanding than simply stating that price would be affected either by costs or by demand. In contrast to Quotation 3 which just focuses on the school perspective, Quotation 6 explicitly considers the behaviour of other businesses in the 'general market' (such as Costa), although it is notable that only one type of market is considered (the coffee shop market). There is no mention of the market for coffee beans, for example. Therefore, this quotation is taken to represent Conception C2 in Table 2.0.

Quotation 7 explicitly refers to 'market forces' and the interaction between supply and demand. This graduate also acknowledges the constraints on that interaction represented first, by differences in market power (in the reference to 'purchasing power') and, second, by considerations of equity (in the reference to Fairtrade). Quotation 7 is therefore illustrative of Conception D2 in Table 2.0.

Quotation 5 (P2) - Conception B2

Some of the factors which will influence price will be from the demand or supply side. On the demand side, factors such as population growth in countries where coffee is popular will affect the price. If the demand is increasing it stands to reason that the price will go up, based on basic supply and demand principles. On the supply side, mechanisation of the supply chain could reduce average unit costs so that price will decrease.

\section{Quotation 6 (P1) - Conception C2}

The price would be dependent upon a number of factors, the cost of materials, the demand, the coffee, the location of other coffee shops and the financial state of the canteen i.e. if costs in general have gone up it would be realistic to marginally increase the price of all products where the products are not price sensitive. People purchasing (coffee) are most likely to buy the product even if price was increased to say 70p. Also in the general market, setting a 
price of say 95p would still be considerably cheaper than purchasing the coffee from others such as Costa.

\section{Quotation 7 (P2) - Conception D2}

The price of any product is affected primarily by market forces - the supply and demand for that product. In theory equilibrium price is where supply equals demand........There is a large inequality in the wealth of the nations supplying coffee and the countries demanding the most coffee. The companies in developed countries can apply a great deal of purchasing power and put down the price farmers get for their coffee. There are also political factors at play though and differences in consumer choice..... it is possible that the coffee price would have been even lower without the Fairtrade movement. Fairtrade doesn't look at the price customers are willing to pay but the price that gives a reasonable standard of living for farmers. This is outside the traditional economics of supply and demand.

Some graduates revealed a conception that did not explicitly include supply and demand factors, and yet seemed to reflect a market context. There were relatively few of these and they were captured by the descriptions of Conception A2 (and A3) in Table 2.0. One group of responses (usually to $\mathrm{P} 1$ ) related to the price charged by the competition and the location of competition as being factors affecting the pricing decision. Quotation 8 below is typical of this type of response. Although competition is an issue affecting customers (and is therefore related to demand) this quotation does have a strong sense of price as being the outcome of broader interaction between businesses as well. The answer even hints at the possibility of working with competition in order fix price through collusion.

In another type of response (usually to P2), graduates made explicit reference to the idea of markets without including supply and demand in their explanations. Quotation 9 is typical. This graduate uses the term 'market' in conjunction with a double use of the phrase 'throughout the world', the term 'demand' twice and the term 'economic'. These are not suggestive of a conception of price as being determined by individuals or businesses and were interpreted as relating to a market-based perspective.

Quotation 8 (P1) - Conception A2

To begin with I would do some market research. Here I could determine how much money consumers are willing to pay at my location......secondly I would consider the price of my competitors. There is little point in me charging $75 p$ if there is a coffee shop next door charging 50p. On the other hand, if they are charging a lot more it may make sense to rise my price or even to collude.

\section{Quotation 9 (P2) - Conception A2}

Factors that influence the price of coffee sold throughout the world would be: economic influences such as demand throughout the world. Demand being high would allow world markets to increase their price. The opposite would happen if demand fell - this would influence countries to sell at a lower price.

A few graduates placed price setting in the context of interaction between markets (Row 3 in Table 2.0). In Quotation 10 the concept of opportunity cost is used to express the way in which supply in one market may change according to opportunities for using resources in 
other markets. In other words, producers will decide to produce coffee if it gives a better return than the outcomes in markets for alternative agricultural crops. However, only the supply side is referred to, so although this is a sophisticated answer in terms of context, it is less sophisticated in terms of interaction between supply and demand. This example indicates that, whilst from a subject knowledge point of view, it is reasonable to see the two dimensions of context and supply and demand as mutually supportive, they can be seen as distinct dimensions of conceptions of price.

\section{Quotation 10 (P2) - Conception A3}

$\$ 6$ will be the price that the producers can produce the coffee for and still make enough profit to merit producing it over other crops. If they were to sell for just \$5 it may well be a large opportunity cost to continue to grow coffee over other goods with a better mark up. $\$ 7$ is likely to be an unacceptable.

Quotation 11 refers to multiple markets in the statement that the coffee 'has gone through many channels' (markets) before it reaches the consumer. It implies that these different markets have different structures where firms have different levels of market power. The market for coffee beans is presented as being less competitive than the market for coffee as a drink. The exact nature of the relationship between markets is not specified, but price is presented as being the outcome of the interaction between them. Whilst many graduates in this study referred to the 'mark-up' that sellers would aim for, Quotation 11 describes the ways in which market power might affect this mark-up. It is therefore taken to be illustrative of Conception D3 in Table 2.0.

\section{Quotation 11 (P2) - Conception D3}

Before coffee reaches the consumer, it has gone through many channels; farmer right through to wholesaler and retail shops. The reason why the price is $\$ 6$, is that wholesalers/manufacturers can take advantage of farmers because they are vulnerable ...... wholesalers control the market. Another aspect of this is the supply and demand of the market, and the fact that consumers can shop around for the cheapest price of a cup of coffee. This is not a monopoly market.

Quotation 11 can be contrasted with Quotations 7 and 4 above. In Quotation 7 there is no recognition of the influence of multiple markets, although there is an acknowledgement that price will be partly determined by issues of equity that lie 'outside the traditional economics of supply and demand'. Quotation 4 emphasises the monopoly power that the school canteen is able to exert, but recognises that 'a consideration must be made with regards to the customer'. This quotation suggests that even though there are interactions between buyer and sellers that are constrained by market power, the ultimate decision about price is taken by the school canteen business.

\subsection{The distribution of graduates' conceptions}

Chart 1.0 shows the percentage of graduates displaying each conception in response to either Problem 1, relating to the school canteen $(n=57)$ or Problem 2, relating to the market for coffee beans $(n=61)$. The dotted line shows that responses to Problem 1 were clustered around the most straightforward conceptions of the external horizon (particularly A1 and 
B1). For example, $55 \%$ of graduates given the price problem set in the school canteen held Conception B1. The dashed line shows that responses to Problem 2 were clustered around more sophisticated conceptions (particularly B2, C2 and D2).

Overall, 75\% of graduates responding to Problem 2 revealed conceptions B2, C2 and D2, whilst $90 \%$ of graduates responding to Problem 1 revealed conceptions A1, B1, C1 and D1. This suggests a strong association between the price problem that was set and the quality of conceptions that were revealed. Although the study did not control for individual graduates' ability, these were all graduates with at least an Upper Second class first degree.

Chart 1.0 also shows that some graduates responded with business based conceptions (Row 1 in Table 2.0) to a market based problem (Problem 2) and with market based conceptions (Rows 2 and 3 in Table 2.0) to a business based problem (Problem 2). For example, $15 \%$ of graduates given Problem 2 exhibited a business based conception. This evidence suggests that although context exerts a strong controlling effect over the conceptions that are revealed, it is to some degree separable from those conceptions.

Chart 1.0 - The distribution of graduates' conceptions of price $(n=118)$

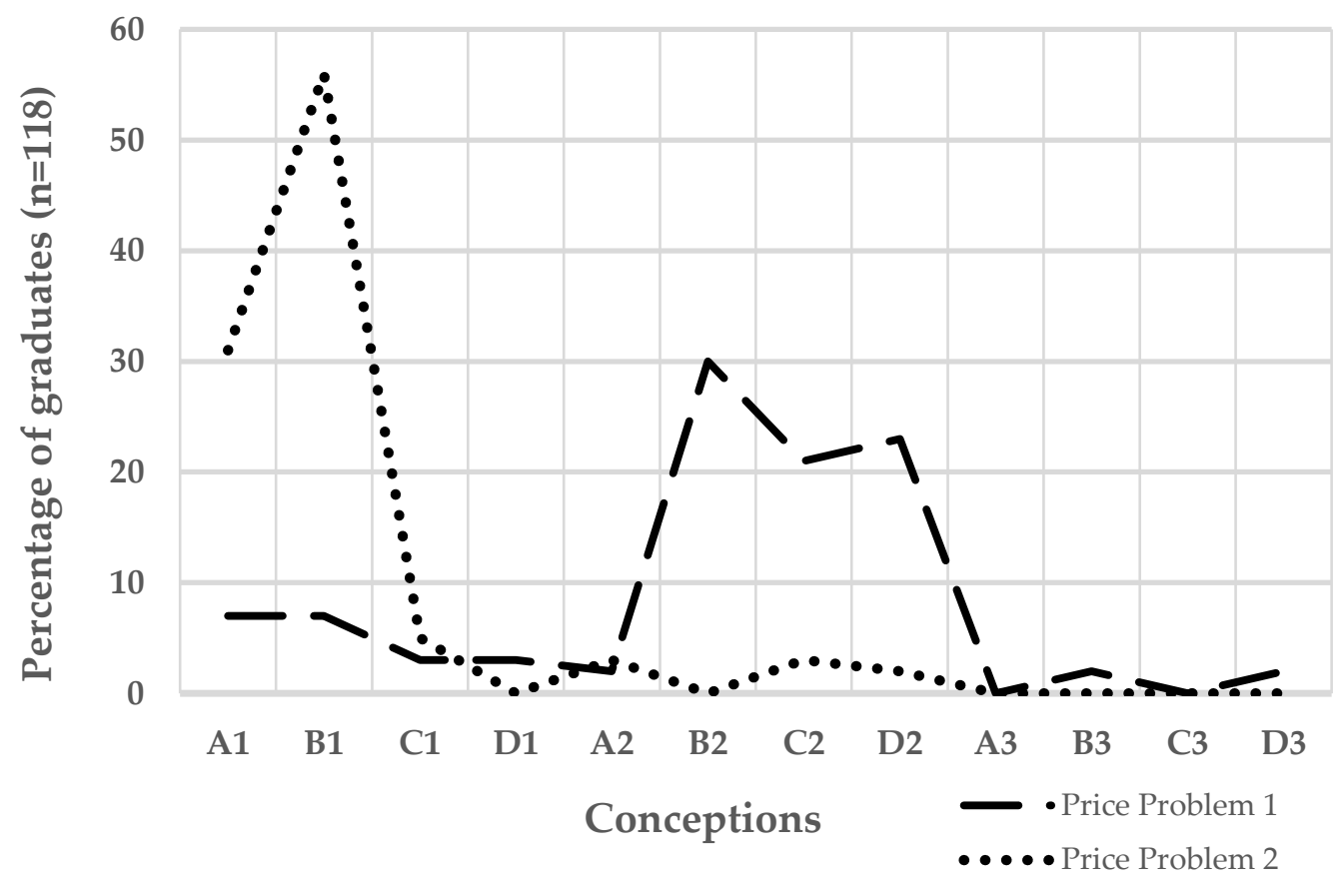

\section{Discussion}

The conceptions of price outlined in Table 2.0 are in line with previous studies. Those along the internal horizon broadly confirm the findings of research by Pang and Marton (2005) and others. Those along the external horizon echo the distinction between market and non-market conceptions of price highlighted by Davies (2011). Differences (e.g. the 
addition of Column D and the absence a low level conception related to features of the product) are likely to have resulted from the focus on graduates in this study. Previous studies of price have focused on school students or undergraduates.

This study found that graduates' conceptions of price were best described in terms of a combination of the internal and external horizons. In other words, there are common features of the phenomenon of price that are identifiable in the different contexts within which it occurs, but that it is not possible to fully describe those conceptions without reference to a particular context. The layout of the grid in Table 2.0 captures this by describing the conceptions (along the internal horizon - Columns A - D) that are visible in each contextual frame (along the external horizon - Rows 1 - 3). This means, for example, that the interaction of supply and demand would be present as an underlying process in the context of both an individual market and multiple markets, but that it would mean something different in each case.

Evidence for this structure is found not only in what graduates' said and wrote but also in the distribution of conceptions. The separateness of the internal and external horizons is shown in the way in which some graduates' were not constrained by the context and, for example, revealed market based conceptions to business based problems. The connectedness of the internal and external horizons is suggested by the powerful effect that the context has on revealed conceptions (see Section 4.3). There is also evidence that market based conceptions are more sophisticated than business based conceptions (reflected in the organisation of Rows $1-3$ ). This is shown in the lower percentage of graduates who responded to the business based price problem with a market based conception of price, compared to those who responded to a market based problem with a business conception of price.

These findings are consistent with the principles of PVT in that they explain the external horizon as an outcome space within which people hold more or less sophisticated conceptions. This moves beyond defining the context as a fixed set of relationships and supports the results of Taylor \& Booth's (2015) study in science education. Providing a theoretical account of this in terms of Gurwitsch's structure of awareness model does not seem to be straightforward. In order for a person to hold a conception of the external horizon, PVT requires that it is defined as a phenomenon. However, treating the external horizon as a phenomenon means that it needs to be in some way separate from (although connected to) the phenomenon that is related to the internal horizon. The structure of awareness model requires modification to explain this since it: i) only analyses one phenomenon at a time and, ii) proposes that the 'theme' is drawn from the 'thematic field' (rather than being a combination of themes from different thematic fields).

In line with Taylor \& Booth (2015), this study found that conceptualising the external horizon as a separable entity and including this in research design reveals aspects of conceptions that may not be easily revealed otherwise. This approach could contribute to the validity of PVT research by allowing easier and better informed scrutiny of results (Cope, 2004). In contrast to Taylor \& Booth (2015) however, this study incorporated the external horizon at two points in the research. Firstly, the context was varied during the collection of evidence in the use of two carefully developed contextualised price problems 
and secondly, contextual aspects were at the forefront of researchers' minds during the analysis of that evidence. Including the external horizon at both stages could generate a greater variation in revealed conceptions, given the 'controlling' effects of context suggested in Chart 1.0 above.

This could have important implications for the application of PVT to teaching. If consideration of the context results in more complete descriptions of conceptions, then teachers' knowledge of students' conceptions will be improved. This will allow them to focus more accurately on the critical aspects in their teaching. Specifying an object of learning more comprehensively has been shown to help teachers have more impact on student learning (Kullberg, Mårtensson \& Runnesson, 2016). A consideration of the context of phenomena in the manner suggested in this paper could contribute to this.

A two dimensional grid allows teachers to map out critical aspects along both external and internal horizons and therefore become more aware of the boundaries of phenomena. PVT assumes that learning occurs through the experience of difference against a background of sameness (Marton, 2015). If teachers can clearly distinguish between the internal horizon and the external horizon, then there is a better chance that they can maintain an invariant background against which their students can experience variation. For example, since the results of this study suggest that different products do not necessarily represent different contexts, teachers who assume that holding the product invariant is the same as holding the context invariant are less likely to focus on variation in the 'right' critical aspects to promote deeper understanding.

In addition, this study confirms the idea that if teachers are not aware of the external horizon, they could inadvertently limit students' ability to achieve a more sophisticated level of understanding (Davies, 2011). For example, a teacher who sets a price problem in a business or individual context (such as the school canteen) is much less likely to trigger the acquisition of conceptions related to a multiple-market conception than if they set the problem in a multiple-market context (such as the market for coffee beans). With an improved knowledge of context, teachers would be better able to avoid this situation.

The results of this study raise a number of questions which suggest that the theoretical framework for describing conceptions may be incomplete. First is the issue of how conceptions should be ranked. This is particularly important for applications of PVT to instructional design, such as Learning Study, where the success of an intervention is measured by the extent to which the quality of students conceptions is changed (Pang \& Marton, 2003). This challenge can be illustrated by referring to Table 2.0. Here, for example, it is possible to say with confidence that Conception A1 is less sophisticated that Conception D3, but it is harder to say whether Conceptions A2 and B1 are of equal sophistication. This is because the 'jump' between Conceptions A1 and A2 and between Conceptions A1 and B1 might not be equal. The size of the differences between categorically different conceptions comes into sharp relief when the structure of conceptions is found to be arranged in a grid. Accounting for this in a two dimension grid is problematic. 
This is further complicated if there are relationships between the internal and external horizons that are not easy to represent in a grid. For example, a move from Column $\mathrm{B}$ to Column C involves a shift from recognising the influence of both 'sides' in price determination to understanding the interactions between the two. This may be more easily facilitated if it is associated with a move from Row 1 to Row 2 (where the difference between a non-market and market context is highlighted). If this is the case, it is possible that students exposed to variation in critical features along the internal horizon (as would commonly be the case in lessons on price designed around the results of previous PVT research) may not be able to progress at all, or as quickly, to higher conceptions if they are not exposed to variation in critical features along the external horizon. This could have significant implications for teachers in trying to establish what the 'correct' sequencing of variation should be.

\section{Conclusion}

This study has followed the conventions of phenomenographic research, but explicitly built in a conceptualisation of the context as being separable (although related) to conceptions of a phenomenon (in this case, price). This involved: i) identifying critical aspects in the context of a phenomenon that were supported by previous research, ii) systematically varying these during the research process in both the written problems given to graduates and in the semi-structured interviews that were conducted and, iii) being alive to the possibility of making reference to them in descriptions of conceptions. These three steps are consistent with PVTs' aim of revealing the widest possible variation in peoples' conceptions.

This process has resulted in descriptions of conceptions of price that are different in their structure (and aspects of their content) to previous descriptions, although in identifying qualitative differences within the external horizon as well as the internal horizon, they are consistent with the general principles of PVT. The findings are lent weight by the empirical work by Taylor \& Booth (2015), by the more theoretical approach taken by Cope (2004), and by the previous PVT research into price and its context (e.g. Davies, 2011).

The proposed structure is useful in explaining the way in which people can identify the same phenomenon in different contexts. The grid format allows a distinction to be drawn between a critical aspect of a phenomenon that is relevant to a particular context and one that is not (Marton \& Pong, 2005). Both of these are very helpful in the design of teaching strategies that are effective in promoting conceptual change. They enhance teachers' knowledge, allowing them to more accurately identify the critical aspects in students' conceptions. This means they can be more certain about the correct patterns of variance and invariance to establish, as well as making sure that they do not choose contexts that might limit students' ability to develop more sophisticated conceptual understanding.

However, the proposed structure of conceptions raises questions about how to: i) theorise the combination of components from the internal and external horizons and, ii) rank conceptions and develop appropriate patterns of variation to effectively apply variation theory to those conceptions. This second point is particularly important for practical 
applications of PVT, such as Learning Study, that rely on accurately specifying qualitative differences in conceptions in order to underpin the design of instructional strategies and the measurement of their effectiveness.

\section{References}

Abreu Novais, M., Ruhanen, L. and Arcodia, C. (2018) 'Destination competitiveness: A phenomenographic study', Tourism Management. Elsevier Ltd, 64, pp. 324-334. doi: 10.1016/j.tourman.2017.08.014.

Åkerlind, G. S. (2005) 'Variation and commonality in phenomenographic research methods', Higher Education Research \& Development, 31(1), pp. 115-127. doi: 10.1080/07294360.2011.642845.

Arveklev, S. H. et al. (2018) ‘Nursing students experiences of learning about nursing through drama', Nurse Education in Practice. Elsevier Ltd, 28, pp. 60-65. doi: 10.1016/j.nepr.2017.09.007.

Ashworth, P. and Lucas, U. (2000) 'What is the "World" of Phenomenography?', Scandinavian Journal of Educational Research. Taylor \& Francis Group, 42(4), pp. 415-431. doi: $10.1080 / 0031383980420407$.

Bera (2011) 'Ethical Guidelines for Educational', British Educational Research Association. doi: 978-0-946671-32-8.

Bowden, J. A. and Walsh, E. (2000) 'Phenomenography', in Phenomenography. Melbourne: RMIT University Press.

Cope, C. (2004) 'Ensuring validity and reliability in phenomenographic research using the analytical framework of a structure of awareness', Qualitative Research Journal, 4(2), pp. 518.

Cope, C. and Prosser, M. (2005) 'Identifying Didactic Knowledge : An Empirical Study of the Educationally Critical Aspects of Learning about Information Systems \& MIKE PROSSER2', 49(3), pp. 345-372. doi: 10.1007/s10734-004-6677-x.

Dahlgren, L. et al. (2006) 'Conceptions of learning and teaching among teachers and students in higher education', Anthology of Social and Behavioural Sciences, pp. 625-633.

Davies, P. (2011) 'Context and structure in conceptual change: students' understanding of price', in Paper presentation at the Department of Education, Stockholm University.

Davies, P. (2011) 'Students' conceptions of price, value and opportunity cost: some implications for future research', Citizenship, Social and Economics Education, 10(2), p. 101. doi: 10.2304/csee.2011.10.2.101.

Gurwitsch, A. (1964) The field of consciousness. Pittsburgh: Duquesne University Press. Kullberg, A., Mårtensson, P. and Runesson, U. (2016) 'What is to be Learned? Teachers' 
Collective Inquiry into the Object of Learning', Scandinavian Journal of Educational Research, 60(3), pp. 309-322. doi: 10.1080/00313831.2015.1119725.

Lo, M. L. (2009) 'Building a teacher learning network for developing the abiity to teach for learning', in Paper presented at the 13th biennial conference of European Association for Research on Learning and Instrution. Amsterdam.

Lo, M. L. and Chik, P. P. M. (2016) 'Two Horizons of Fusion', Scandinavian Journal of Educational Research, 60(3), pp. 296-308. doi: 10.1080/00313831.2015.1119730.

Lo, M. L. and Marton, F. (2012) 'Towards a science of the art of teaching: using variation theory as a guiding principle of pedagogical design', International Journal for Lesson and Learning Studies, 1(1), pp. 7-22.

Markauskaite, L. and Wardak, D. (2015) 'Research students' conceptions of the role of information and communication technologies in educational technology research', Australasian Journal of Educational Technology, 31(4), pp. 421-438.

Marton, F. (2015) Necessary conditions of learning. London: Routledge.

Marton, F. and Booth, S. (1997) Learning and awareness. Nahwah N.J.: Lawrence Erlbaum.

Marton, F. and Pang, M. F. (2008) 'The idea of phenomenography and the pedagogy of conceptual change', in International handbook of research on conceptual change. London: Routledge, pp. 563-576.

Marton, F. and Yan Pong, W. (2005) 'On the unit of description in phenomenography'. doi: 10.1080/07294360500284706.

Morrison, C. and Secker, J. (2017) 'Understanding librarians' experiences of copyright', Library Management, 38(6/7), pp. 354-368. doi: 10.1108/LM-01-2017-0011.

Pang, M. F., Linder, C. and Fraser, D. (2006) ‘Beyond Lesson Studies and Design Experiments - Using Theoretical Tools in Practice and Finding Out How They Work', International Review of Economics Education, 5(1), pp. 28-45. doi: 10.1016/S14773880(15)30126-2.

Pang, M. F. and Marton, F. (2003) 'Beyond "lesson study": Comparing two ways of facilitating the grasp of some economic concepts', Instructional Science. Springer, 31, pp. 175-194. doi: 10.2307/41953614.

Pang, M. F. and Marton, F. (2005) 'Learning Theory as Teaching Resource: Enhancing Students? Understanding of Economic Concepts', Instructional Science, 33(2), pp. 159-191. doi: 10.1007/s11251-005-2811-0.

Prosser, M. (2000) 'Using phenomenographic research methodology in the context of research in teaching and learning', in Bowden, J. and Walsh, E. (eds) Phenomenography. Melbourne: RMIT University Press, pp. 24-32.

Rovio-Johansson, A. and Ingerman, A. (2016) ‘Continuity and Development in the Phenomenography and Variation Theory Tradition', Scandinavian Journal of Educational 
Research, 60(3), pp. 257-271. doi: 10.1080/00313831.2016.1148074.

Taylor, D. L. and Booth, S. (2015) 'Secondary Physical Science Teachers' Conceptions of Science Teaching in a Context of Change', International Journal of Science Education, 37(8), pp. 1299-1320. doi: 10.1080/09500693.2015.1035356.

Wilhelmsson, N. et al. (2011) 'On the anatomy of understanding', Studies in Higher Education, 36(2), pp. 153-165. doi: 10.1080/03075070903514054. 